\author{
Military Technical College \\ Kobry El-Kobbah, \\ Cairo, Egypt.
}

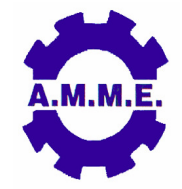

\title{
IMPROVEMENT OF OFF-ROAD VEHICLES PERFORMANCE USING CONTROLLABLE TORQUE DISTRIBUTION DEVICE
}

\author{
M. M. Abd El-hafiz , S. Shaaban ${ }^{* *}$, W. A. Oraby ${ }^{* * *}$, M. A. Emam ${ }^{\dagger}$ and A. M. Sharaf ${ }^{\dagger \dagger}$
}

\begin{abstract}
A peculiarity of off-road vehicles is that their mobility depends not only on the total power provided by the engine, but also on its distribution among the driven axles/wheels. In turn, this distribution is largely dominated by the drivetrain architecture and the inherent characteristics of the torque distribution devices. Among the wide variations of torque distribution devices, controlled differential can offer variable bias ratios over the entire operation of the vehicle.

This paper presents an electronically controlled device to modulate the applied force over multi-plate clutches which are placed between the driven axle and stationary hub. For the driving condition over split adhesion roads, the proposed device brakes the spinning wheel over low adhesion side and therefore bias more torque to the other wheel with good adhesion side. This would improve off-road mobility and save the power losses on low traction wheels. A special test rig has been devised to experimentally investigate the characteristics of the proposed device. The rig compromises measurements of speed and torque applied to each wheel.
\end{abstract}

The obtained results show that various benefits could be gained when a controllable multi plate clutch is implemented with simple differential driving axle. The system can offer power saving than both passive differential and even limited slip differential.

\section{KEY WORDS}

AWD Torque distribution devices - Controllable differentials

\footnotetext{
Ass. Lecture, Automotive Eng. Dept., Faculty of Eng. - Mataria, Helwan Univ., Cairo, Egypt.

** Professor, Automotive Eng. Dept., Faculty of Eng. - Mataria, Helwan Univ., Cairo, Egypt.

*** Ass. Professor, Automotive Eng. Dept., Faculty of Eng. - Mataria, Helwan Univ., Cairo, Egypt.

$\dagger \quad$ Lecturer, Automotive Eng. Dept., Faculty of Eng. - Mataria, Helwan Univ., Cairo, Egypt.

t† Egyptian Armed Forces.
} 


\section{INTRODUCTION}

Off-road vehicles such as all terrain vehicles (ATV) often get stuck up in muddy trenches or in low adhesion terrains with one of wheels in the trench and the other on level ground [2]. During turning maneuvers, open differentials perform well provided that the driving torque is equally distributed among its wheels. However, if the road condition on one side of the road is slippery or if one wheel gets significantly less vertical load than the other, this wheel would spin fast wasting most of the engine power in the form of the frictional heat. As a result the vehicle would lose its traction and the driver has to reduce the engine power to save the tire [4]. Differential-lock provides the ultimate traction because of the ability to bias all available torque to one wheel. Differential-lock must be disabled when turning to prevent dangerous handling conditions.

Limited slip differentials (LSD) offer significant performance benefits over standard differentials. Over the years, several types of limited slip differentials have been developed compromising the torque output whenever excessive slip or speed difference occurs. However, most limited slip differentials are tuned to meet one situation only and can be only optimized in favor of traction performance or handling characteristics. If the differential is tuned for handling characteristics, mobility will be compromised, due to the moderate tuning. To optimize the performance, tuning must be adjustable according to the vehicle's design parameters [3].

The common types of LSD according to principle of operation are torque sensitive and speed sensitive LSD. Torque sensitive differentials bias torque as a function of the torque available at the slipping wheel. These differentials typically have fixed bias ratios for torque transfer, limiting their effectiveness; if a wheel is off the ground with no torque, the differential can bias nothing to the good wheel. For this reason, many torque sensitive differentials are designed with preload. Even with a wheel off the ground, there is some torque available to the wheel with good traction. Speed sensitive differentials bias torque based on the speed difference between the drive wheels, it transfer a fixed amount of torque proportional to the speed difference which provides improvements in mobility and possibly handling [3].

Electronically control differential have been introduced to minimize the conflict between traction and handling requirements such that regulating the distribution of driving torque among axles is achieved through controlled multi-disc clutch [9]. The control device regulates the infinitely variable distribution of the drive torque between the front and rear axles resulting in a longitudinal distribution of the drive torque or between right and left wheels in cornering or split adhesions. The system can be implemented in two ways; inter-axle and inter-wheel driving control systems as shown in Figs 1\& 2. In the inter-axle control system, the distribution of the driving torque can be regulated among the front and rear axles as shown in Fig. 3, while in inter-wheel control system the system can modulates the torque until $100 \%$ of the torque transferred to the rear axle as shown in Fig. 4 . There is $75 \%$ of drive torque available for pulling away (50\% at right rear wheel, plus $25 \%$ at right front wheel) this is due to the front axle equipped with conventional differential without control. 


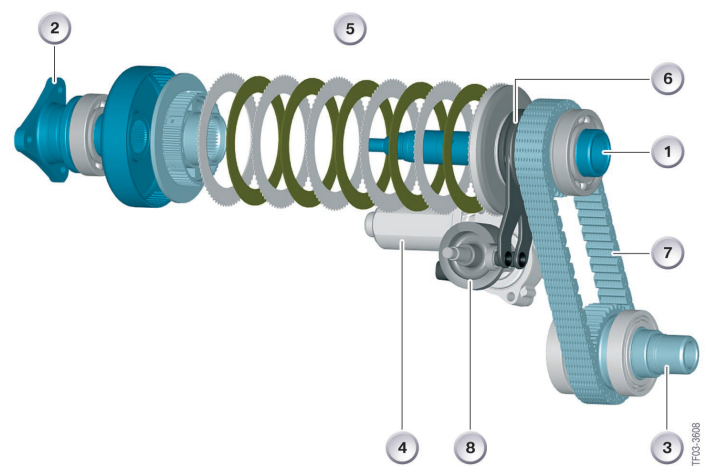
1. Input from gearbox
2. Output to rear axle
3. Output to front axle
4. Servomotor
5. Set of discs
6. Adjusting levers with ball ramp
7. Chain
8. Disc cam

Fig.1. Inter-axle multi plate clutch traction control [9].

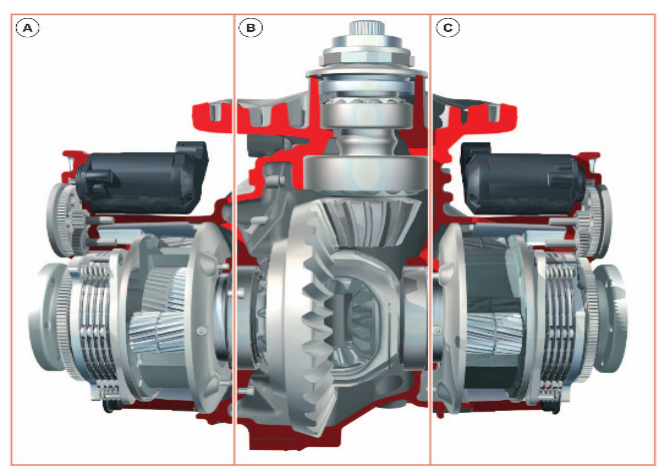
A. Left controllable clutch
B. Simple differential
C. Right controllable clutch

Fig.2. Differential with inter-wheel traction control [9].
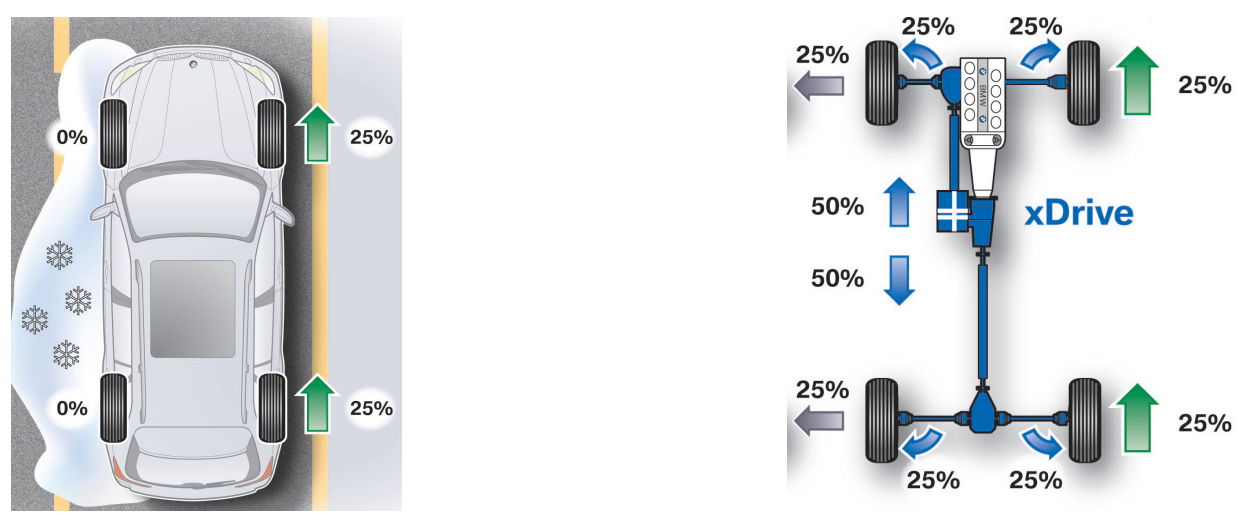

Fig.3. Vehicle in split adhesion with inter-axle traction control and normal inter-wheel differential [9].
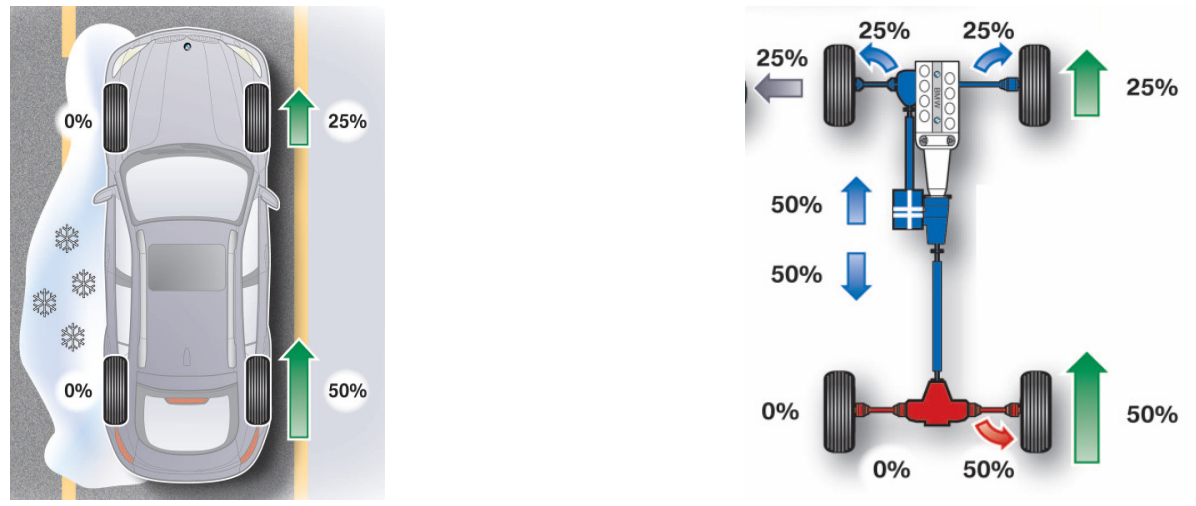

Fig.4. Vehicle in split adhesion with inter-axle plus inter-wheel traction control [9]. 


\section{THE PROPOSED TORQUE DEVICE}

An electronically controlled multi-plate friction clutches system is placed between the conventional differential and traction wheels. The torque device is shown in Fig. 5 and consists of 8 pairs of wet metal (steel) friction clutch which are similar to those used in limited slip differentials. The plates are stacked in an alternate arrangement inside cylindrical steel housing and splined hub fixed with the driven axle between the differential and wheel side. Half of these plates are driven with a splined shaft and the other are connected to the stationery housing.

The plates are compressed together through the applied axial force exerted by a stepper motor. This barking torque depends on the number and dimension of friction plates and the modulated axial force by the stepper motor. To increase the applied axial force on the friction plates, a pair of helical gears with reduction 2:1 is placed. The stepper motor is electronically controlled by a control unit. A LABVIEW program is used to analyze the sensed data (torque, speed) and control the stepper motor with the required angle according to slipping wheel. The angular displacement of the motor is transferred to liner displacement through the thread between the sleeve (4) and Clutch housing front cover (5).

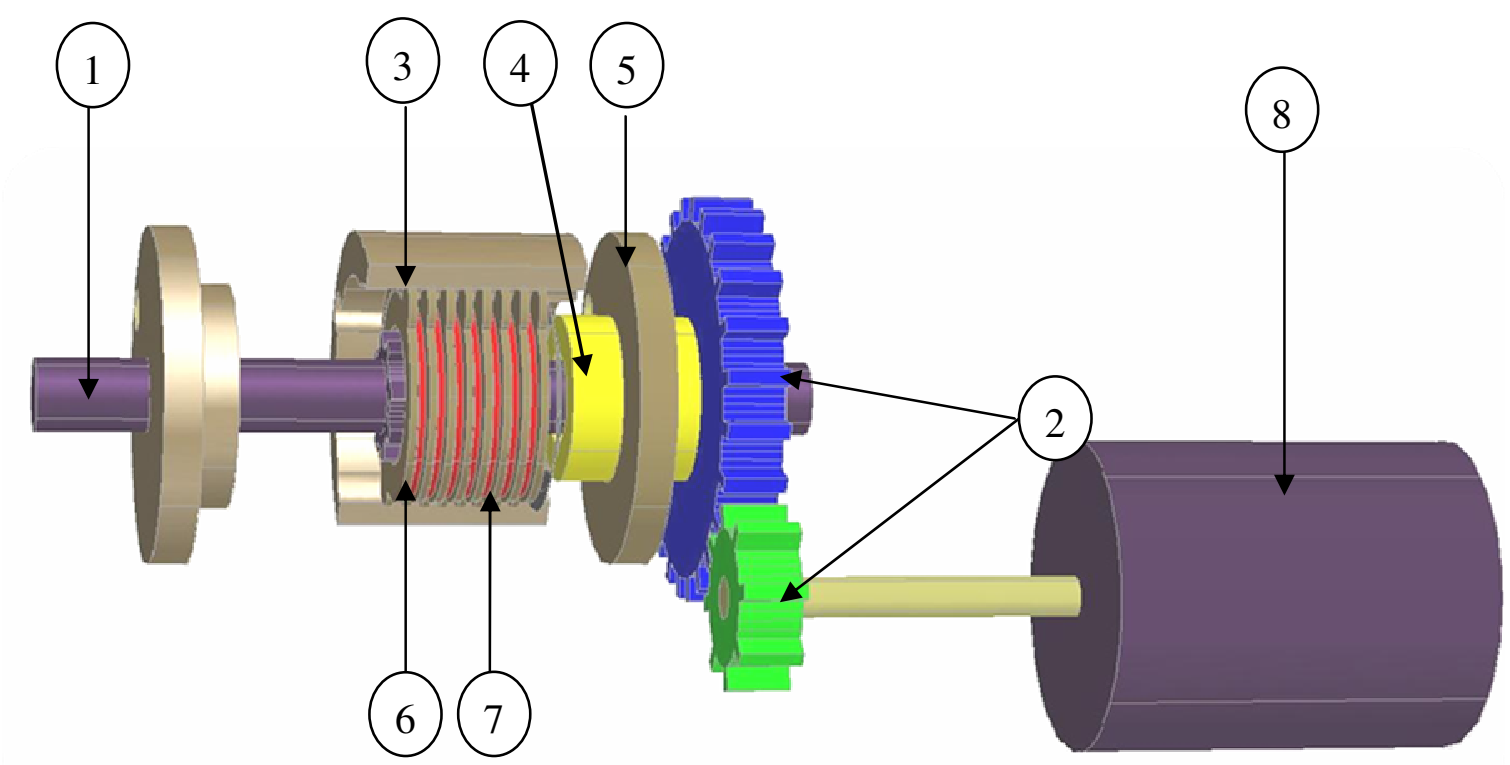

1- Driving axle shaft with spline.

2- Spur gear with screw hub.

3- Clutch housing.

4- Applying force sleeve with outer thread.
5- Clutch housing front cover with inner thread.

6- Friction clutch outside part.

7- Friction clutch inside part.

8- Stepper motor.

Fig.5. Inter-wheel or inter-axle controllable clutch system. 


\section{TEST RIG}

To experimentally testify the presented torque distribution device shown in Fig. 6, the following test rig is developed. The test rig comprises typical rear axle of all wheel drive (AWD) off-road vehicle with an open differential. A three phase AC motor with $20 \mathrm{hp}$ is used to drive the axle. In addition, brake loading mechanism is introduced to simulate road with different resistances on both left and right sides of the drive axle. The test rig is equipped with following torque sensor and speed sensor for measurement of torque and speed of both the left and right half-shaft. Wheel speed is measured by two photoelectric tachometers. The torque produced on both driven axle sides are measured using strain-gauges.

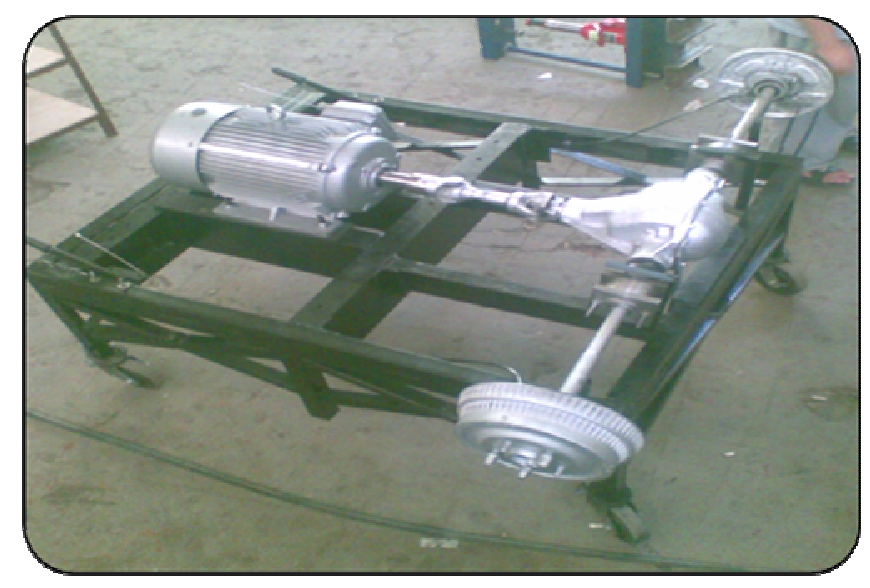

Fig.6. Test rig layout off-road driving axle with controllable clutch mechanism.

For the measurement of torque applied on both left and half shafts, four strain gages (Biaxial, $120 \mathrm{ohm}, 10$ volt excitation) are bonded on each driving axle as shown in Fig. 7. The strain gages are connected together $(2 \times 2)$ to make $45^{\circ}$ with the force line and $90^{\circ}$ to each other. A Wheatstone bridge method is used to connect the gages to give four terminals two of them for excitation and the other for output reading.

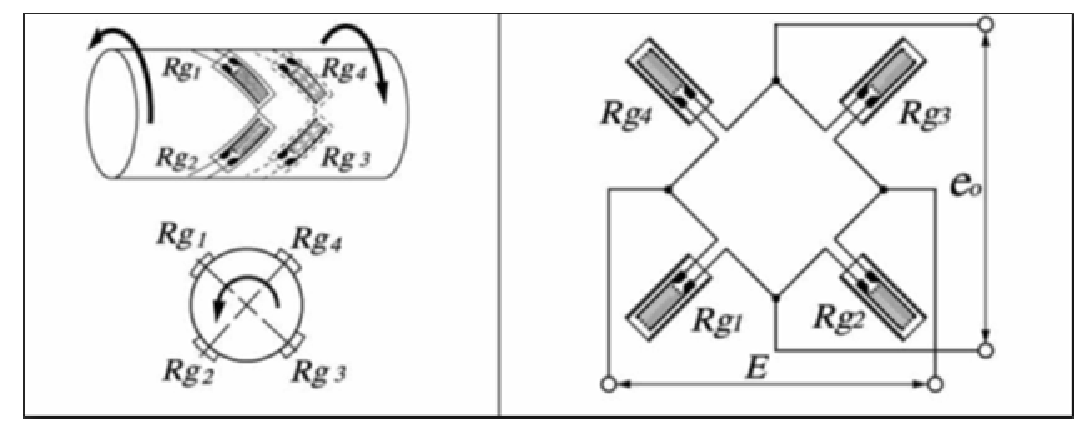

Fig.7. Arrangement of strain gauges for measuring axle shaft torque. 
The torque is directly proportional to the strain of the driving axles; furthermore shearing stress distributed on the lateral section is balanced with the applied torque. The axle torque can be calculated from measured strain as follows:

$$
T=\left(\varepsilon_{o} \cdot E \cdot Z_{P}\right)(1+v)
$$

where:

$Z_{p}$ : is the polar modulus of section and given by $\left(\pi d^{3} / 16\right)$

$d:$ is Shaft diameter

$\varepsilon_{0}:$ is the strain value

$\mathrm{E}$ : Young's modulus (for carbon steel $=205 \mathrm{GPa}$ )

$v$ : Poisson's ratio (for carbon steel $=0.28: 0.3$ ).

Data Acquisition device and LABVIEW program shown in Fig. 8 have been used to regulate the reading from speed and torque sensors and analyze the reading then controls the actuators with desert values according to the flow chart in Fig. 9 which is constructed inside the program.
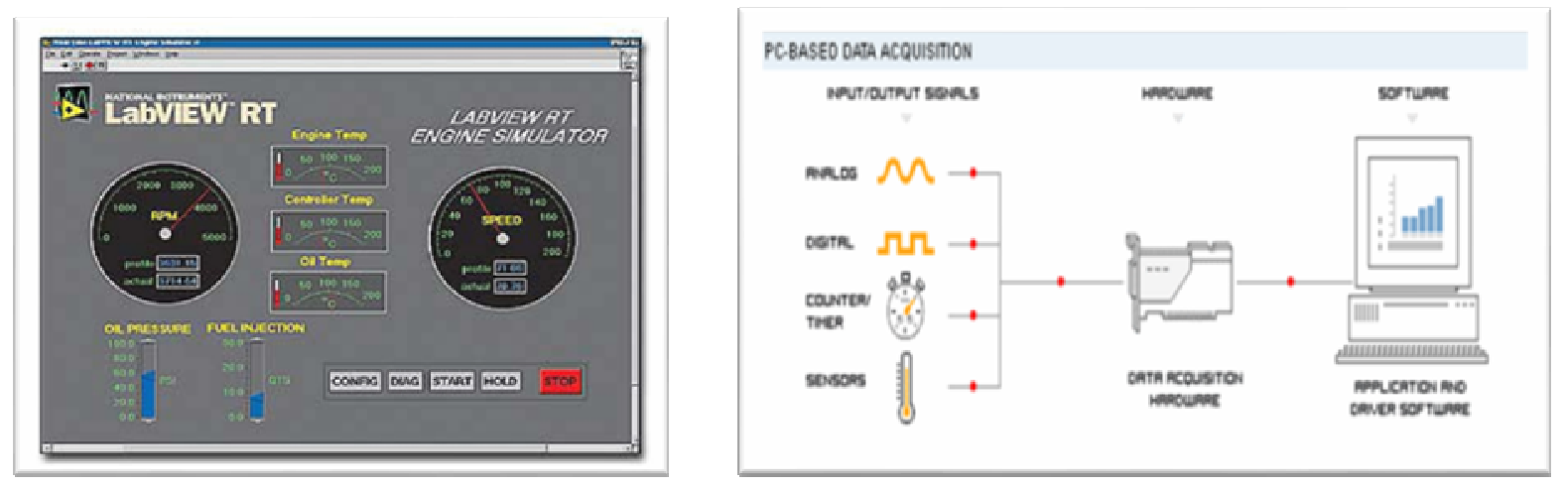

Figure 8. Connection of data acquisition with LABVIEW program and its front panels.

For the purpose of realistic measurements of torque and rotational speed for both left and right axle-shaft, the wheel-brake is applied to simulate the condition of split road adhesion. To show the advantage of the proposed control system, the experiments are considered twice, with and without activating the controllable clutch system.

A hand brake is mounted at each wheel to simulate differential resisting moments. Two levels of resistance are applied to verify the object of proposed control system. The torque and speed on each axle are measured and the speed difference is calculated to indicate the effect of torque distribution on split adhesion. The test is performed on three steps as follow: 


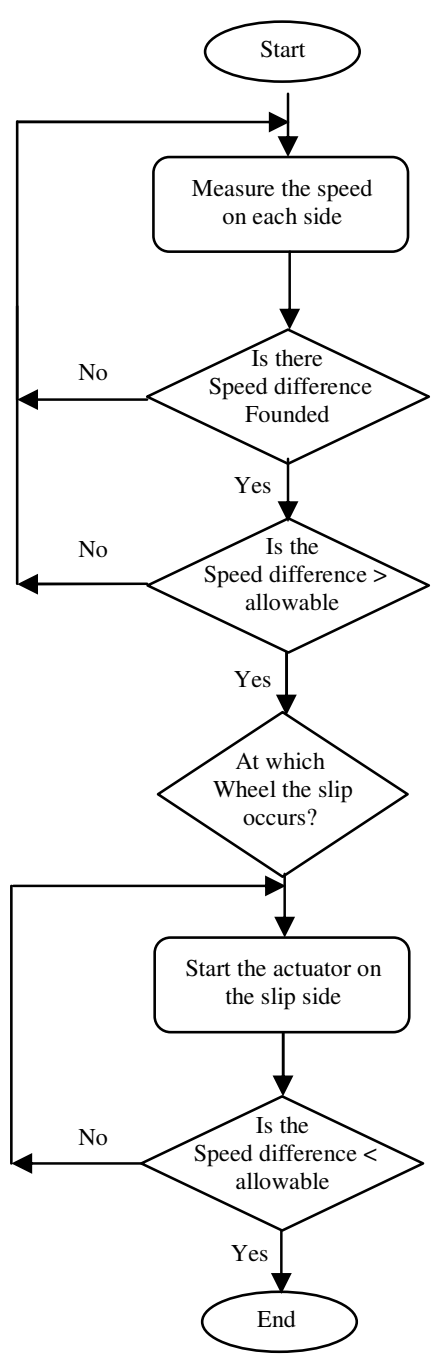

Figure 9 the flow chart that controls the controllable clutch applying force.

I. The brake is partially applied to left wheel to simulate a high adhesion and the right wheel is being free to simulate low adhesion.

II. The brake is partially applied to right wheel similar to that of the left wheel to simulate equal road adhesion.

III. The braking left wheel is increased.

\section{RESULTS AND ANALYSIS}

Figures $10,11,12,13$ show the measurement results of the rotational speed, driving torque, biasing ratio and power at both left and right half-axle respectively without applying the modulating force of the multi-plate clutches. The test procedures are carried out according to the following scheme: 


\begin{tabular}{|c|c|c|c|c|c|c|c|c|c|}
\hline Time (S) & $\mathbf{0 : 2}$ & $\mathbf{2 : 5}$ & $\mathbf{5 : 9}$ & $\mathbf{9 : 1 1}$ & $\mathbf{1 1 : 1 2}$ & $\mathbf{1 2 : 1 6}$ & $\mathbf{1 6 : 1 7}$ & $17: 19$ & $19: 23$ \\
\hline Left Brake & free & Increased & Hold & Decreased & free & free & free & $\begin{array}{c}\text { Increased } \\
\text { intensively }\end{array}$ & Hold \\
\hline Right Brake & free & free & free & free & free & Increased & Hold & Hold & Hold \\
\hline
\end{tabular}

The physical meaning of the aforementioned scheme is to simulate realistic conditions of $\mu$-split surfaces. This would be simply carried out by only applying the wheel brake to one side (good adhesion side), while the other wheel is kept without braking (low adhesion or slippery side). Similar result can be obtained if the applying braking torques at both wheels is not equal.

It should be noted that, whenever the controlled device is off, theoretically the measured torque at each side should be equal (open differential). However, the results show differences in torque values between left and right sides this may be explained to be due to additional frictional resistance of the device which is installed only on the right half-axle. For the practical application of the proposed device, there will be installed similar devices at each axle side; consequently, there will be no difference in torque.

Figures $14,15,16,17$ show the measurements of the rotational speed, driving torque, biasing ratio and power at both left and right half-axles respectively with applying the modulating force of the multi-plate clutch. The test procedures are carried out according to the following scheme:

\begin{tabular}{|c|c|c|c|c|c|c|c|}
\hline Time (S) & $0: 1$ & $1: 5$ & $5: 9$ & $9: 16$ & $16: 20$ & $20: 25$ & $25: 50$ \\
\hline Left Brake & free & Increased & Hold & Decreased & free & $\begin{array}{c}\text { Increased } \\
\text { intensively }\end{array}$ & Hold \\
\hline Right Brake & free & free & free & free & free & free & free \\
\hline
\end{tabular}

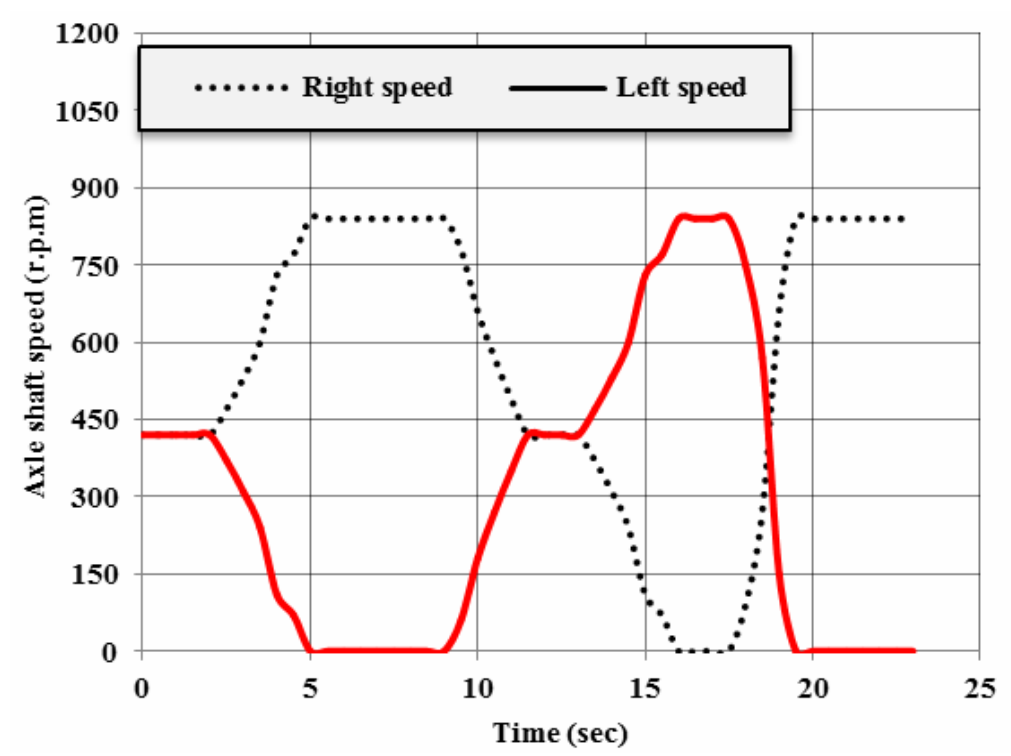

Fig.10. Wheel speeds without controllable device. 


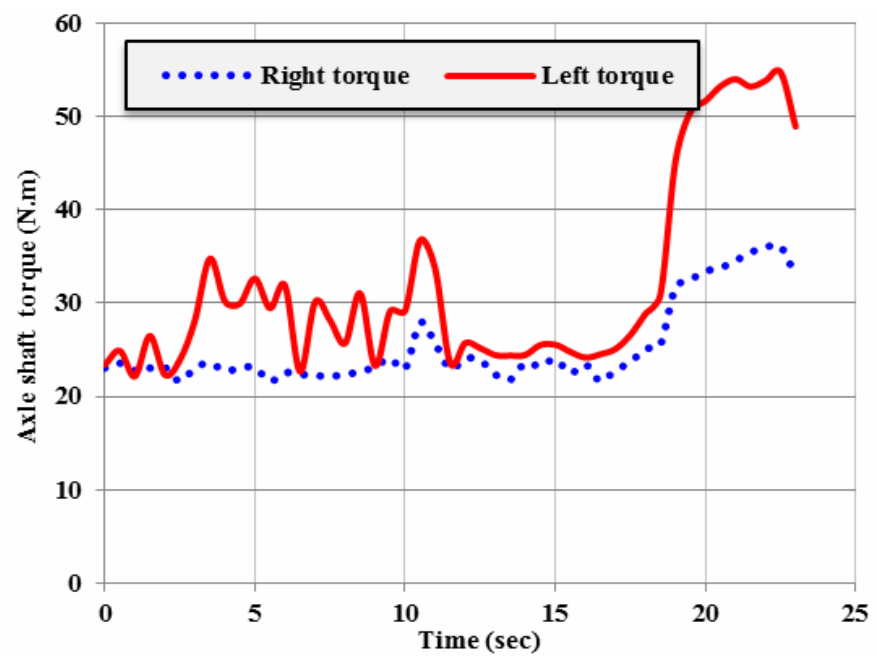

Fig.11. Wheel torque without controllable device.

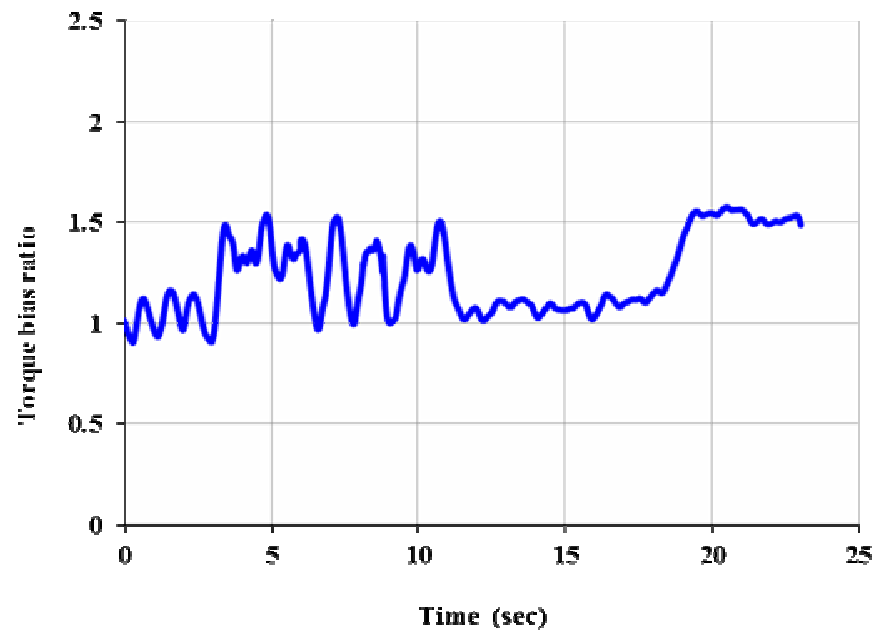

Fig.12. Torque bias without controllable device.

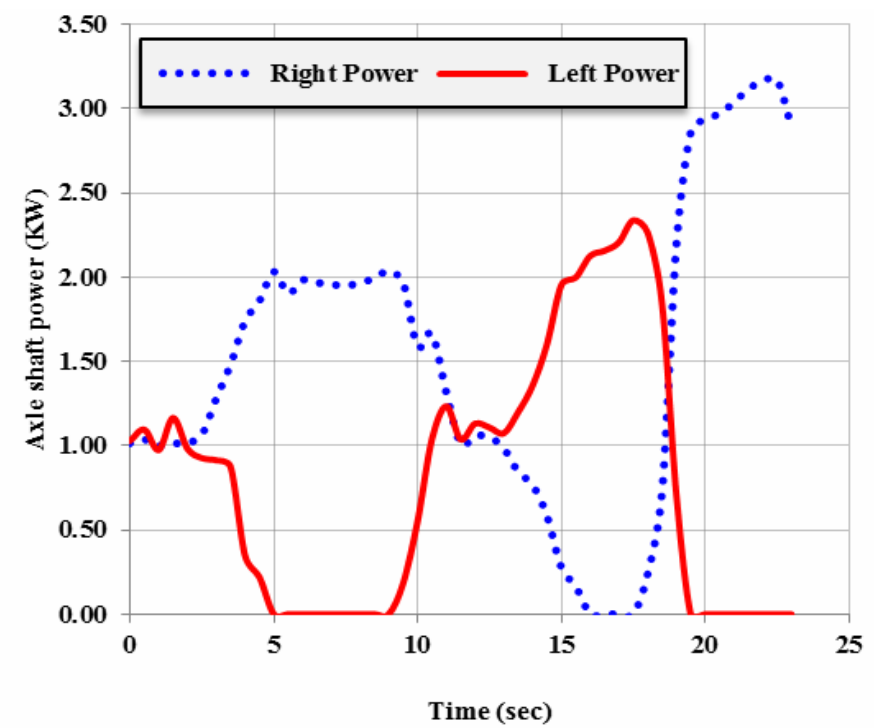

Fig.13. Wheel power without controllable device. 


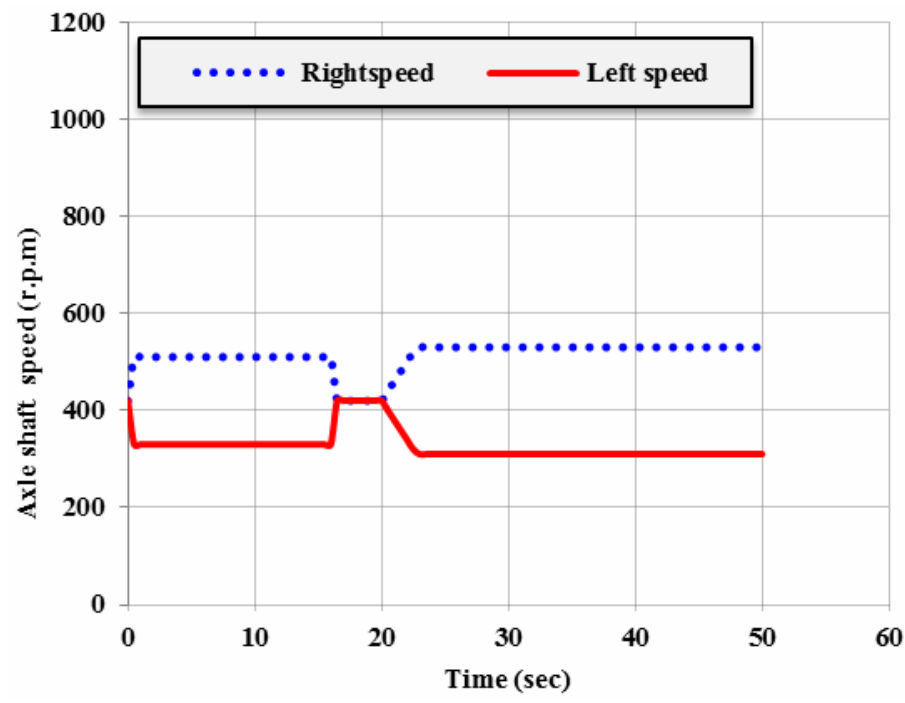

Fig.14. Wheel speeds with controllable device.

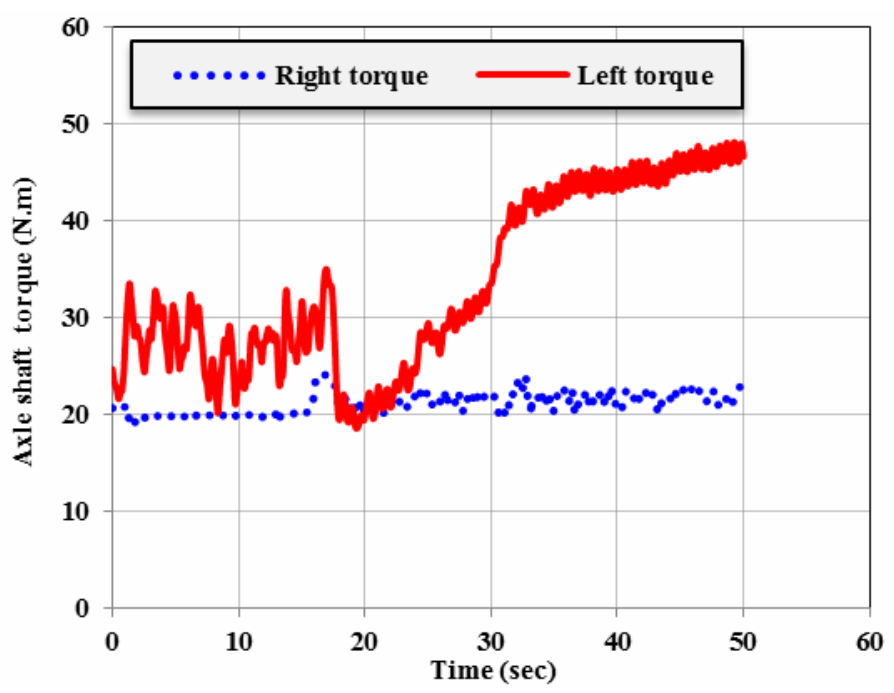

Fig.15. Wheel torque with controllable device.

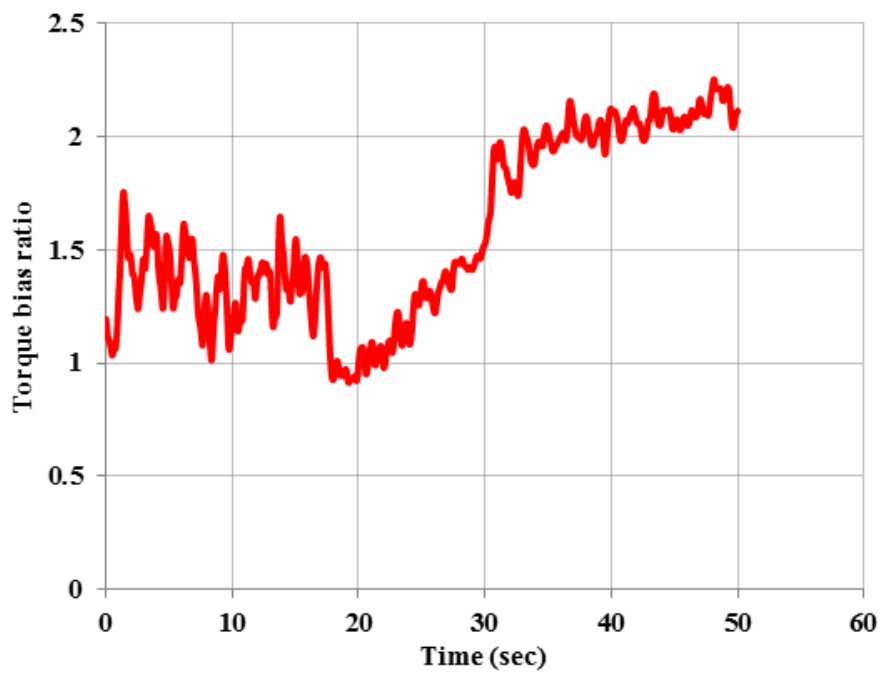

Fig.16. Torque bias with controllable device. 


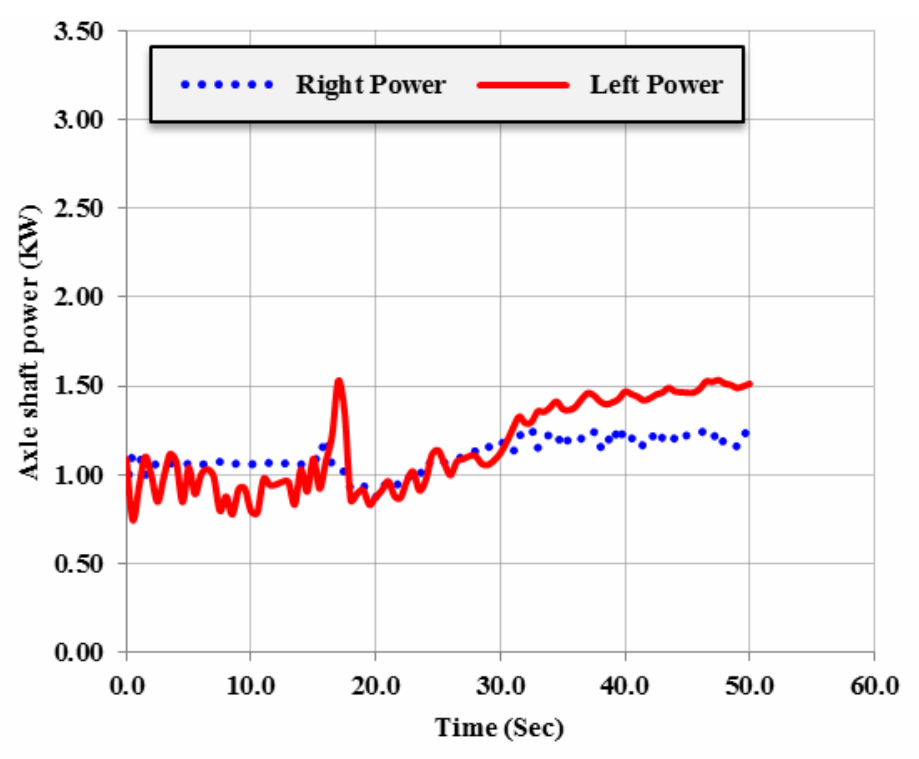

Fig.17. Wheel power with controllable device.

It can be noticed from Fig.14 that, when the rotational speed difference between the left-half and right-half shaft increases above $200 \mathrm{rpm}$, additional barking torque is produced due to the engagement of controlled multi-plat clutches. Therefore, the torque distributed on the wheel on the higher adhesion improves the vehicle traction. This can be clearly noticed from comparison between Fig.12 and Fig.16 where the torque bias is increased up to $40 \%$ with controllable clutch system.

Fig.13 and Fig.17 show the power transmitted to each axle shaft of the driven axle before and after activating the controllable clutch. With controllable clutch unactivated, the whole power is transmitted to the axle with low adhesion while the other axle shaft has no power. However, with activated controllable clutch some power is delivered to the axle with high adhesion which can help the vehicle get out of such difficult driving situation.

\section{CONCLUSION}

The finding of the experimental results shows that torque can be variably distributed between axles by combining a controllable multi plate clutch and a simple differential on a driving axle. In comparison to the driving axle with an open differential, the proposed system offers power saving and better torque bias capabilities.

It should be noted that, further improvements are required to reduce the time response of the system as well higher reduction ratio for the gears to increase the biasing ratio of the device. 


\section{REFERENCES}

[1] Ramanand R. Shetty, Lee B. Arnold and Alf Eriksen, "Progressive Traction Control for Automotive Differentials", SAE paper No. 2000-1-3465.

[2] S. S. Gill, N. S. Kalsi, Balraj Singh and Nirmal Singh, "Improved Differential Function for Avoiding Slippage of Motor Vehicles in a Muddy Trench", SAE paper No. 2002- 1-0988.

[3] Jerry Kinsey, "The Advantages of an Electronically Controlled Limited Slip Differential", SAE paper No. 2004-1-0861.

[4] John Park, Jeff Dutkiewicz and Ken Cooper, "Simulation and Control of Dana's Active Limited-Slip Differential e-Diff", ", SAE paper No. 2005-1 -0409.

[5] Damrongrit Piyabongkarn, Jae Lew, John Grogg and Robert Kyle, "Stability Enhanced Traction and Yaw Control using Electronic Limited Slip Differential", SAE paper No. $2006-1-1016$.

[6] Damrongrit Piyabongkarn, John Grogg, Qinghui Yuan and Jae Lew, "Dynamic Modeling of Torque-Biasing Devices for Vehicle Yaw Control", SAE paper No. $2006-1-1936$.

[7] Pa r Marklund, Rikard Ma ki, Roland Larsson, "Thermal influence on torque transfer of wet clutches in limited slip differential applications", Science Direct, Tribology International, 2007.

[8] Resev, J. Roosimölder, L. Siitas, M. "SWITCHING PROCESS IN LIMITED SLIP DIFFERENTIAL", 6th International DAAAM Baltic Conference, April 2008, Tallinn, Estonia

[9] BMW X3, X5 and X6 group manuals.

[10] Jonathan C. Wheals et al. "Torque Vectoring Driveline: SUV-based Demonstrator and Practical Actuation Technologies", SAE paper No. 2005 - 1 0553. 